\title{
A Study of the Charge Transport Process at Nickel Hydroxide-Gold Modified Electrodes employing Rotating Disc Electrode Voltammetry and Ac Impedance Measurements
}

\author{
Ricardo I. Tucceri ${ }^{*}$ \\ Instituto de Investigaciones Fisicoquímicas Teóricas y Aplicadas (INIFTA), Sucursal 4, Casilla de Correo 16, 1900, La Plata Argentina \\ ${ }^{*}$ Corresponding author: rtucce@gmail.com
}

\begin{abstract}
The aim of the present work was study how the charge-transport process of a nickel hydroxide film electrochemically synthesized on a gold substrate is modified when the electrode is stored without use for long time. It was found that nickel hydroxide films deactivate under storage, that is, films become less conductive than immediately prepared ones (nondeactivated). This study was carried out in the context of the Rotating Disc Electrode Voltammetry (RDEV) and Electrochemical Impedance Spectroscopy (EIS) when the modified electrode contacts an electroactive solution and a redox reaction occurs at the $\mathrm{Au}-\mathrm{Ni}(\mathrm{OH})_{2} \mid \mathrm{ectrolyte}$ interface. Variations of anodic limiting currents with the electrode rotation rate, for both nondeactivated and deactivated films in the presence of the electroactive solute deferasirox (4-(3,5-bis(2-hydroxyphenyl)-1,2,4-triazol-1-yl) benzoic acid) allowed one obtaining a charge transport rate across a nickel hydroxide film, which decreases with the increase of the storage time. Interpretation of impedance spectra obtained at potential values corresponding to the anodic limiting currents on the basis of an impedance model that considers an uniform and nonporous nickel hydroxide film deposited in a conductive substrate and no penetration of redox species (deferasirox) from the solution, allowed one obtaining different interfacial resistances and electron and ion diffusion coefficients for the $\mathrm{Au}-\mathrm{Ni}(\mathrm{OH})_{2}$ lectrolyte system.
\end{abstract}

\section{Keywords}

Nickel hydroxide-gold modified electrodes, Charge-transport process, Electron hopping model, Electron and ion diffusion coefficients

\section{INTRODUCTION}

The nickel hydroxide is an important electroactive material for many applications of interest such as oxidation and determination of carbohydrates and alcohols [1,2], amino acids [3], hydrogen peroxide [4], methane [5], drugs [3] and some other organic and biologically important products [3,5-8]. Also, the material shows high electrocatalytic efficiency towards the oxidation of organic molecules via cyclic mediation electron-transfer processes in alkaline solutions [1,3-8]. The formation of nickel hydroxide on the electrode surface to construct $\mathrm{Ni}$-hydroxide modified electrodes has been achieved, in principle, in several different ways: by electrooxidation of nickel metal via different regimes of applied potential (e.g. potentiostatic, galvanostatic, anodic sweep), by cathodic deposition from a $\mathrm{Ni}\left(\mathrm{NO}_{3}\right)_{2}$ solution on a conductive substrate and by placing a droplet of $\mathrm{Ni}$ (II) solution on the surface of the electrode and evaporating the solvent $[3,5]$. Concerning practical applications, it is often indicated that nickel hydroxide films have good electrochemical properties in terms of conductivity and ion-permeability and also that they present good durability and long-term stability under storage during several weeks. In this regard, it is assumed that the reversible redox response and conducting properties of the modified electrode remain substantially unchanged before and after it have been used. Considering the important applications of nickel hydroxide modified electrodes, not many efforts have been made to study in detail their true stability. The aim of the present work was study the limit of durability of a nickel hydroxide-gold modified electrode and how the electron-transport processes is modified when the electrode becomes stored without use during long time. This study was carried out by employing Rotating Disc Electrode Voltammetry (RDEV) and Electrochemical Impedance Spectroscopy (EIS) for the interesting case where the modified electrode contacts an electrolyte solution containing an electroactive substrate and a redox reaction occurs at the Ni-hydroxide|ectrolyte interface. Deferasirox (4-(3,5-bis(2-hydroxyphenyl)-1,2,4-triazol-1-yl) benzoic acid) was selected as redox substrate in the present analysis. This drug is an oral iron chelator that is used clinically, mainly in patients with thalassemia $[9,10]$. The electrocatalytic oxidation and determination of this drug on a nickel hydroxyde-modified electrode was studied in previous works [11].

\section{EXPERIMENTAL}

A conventional three electrodes cell was used for the experiments. A gold rotating disc electrode (RGDE) was employed as base 
electrode to deposit nickel hydroxide films. A platinum foil of large area was employed as counter electrode. All the potentials reported in this work are referred to the SCE. The RGDE consisted of a gold rod press-fitted with epoxy resin into a Teflon sleeve so as to leave a $0.7 \mathrm{~cm}^{2}$ disc area exposed.

Nickel hydroxide films were deposited on the RGDE employing the following procedure: firstly, the electrode was either cycled between $0.0 \mathrm{~V}$ and $-0.5 \mathrm{~V}\left(20 \mathrm{mV} \mathrm{s}^{-1}\right)$ or subjected to a constant potential of $-0.5 \mathrm{~V}$, in a deaerated $0.5 \mathrm{M} \mathrm{Ni}\left(\mathrm{NO}_{3}\right)_{2}$ solution. Then, the obtained modified electrode was transferred to an electrochemical cell containing a $0.1 \mathrm{M} \mathrm{NaOH}$ solution and it was cycled between $0.0 \mathrm{~V}$ and $0.6 \mathrm{~V}(v s$. SCE) until a stable voltammogram was achieved. These nickel hydroxide modified electrodes are called here, nondeactivated (or immediately prepared). Fig. 1 compares stabilized cyclic voltammograms at a scan rate $0.02 \mathrm{~V} \mathrm{~s}^{-1}$ in a $0.1 \mathrm{M} \mathrm{NaOH}$ solution for nondeactivated nickel hydroxide films of different voltammetric charge. When these immediately prepared nickel hydroxide films are stored (without use) in a deaerated $0.1 \mathrm{M} \mathrm{NaOH}$ solution for different time periods, they undergo a deactivation, which is evident from the gradual reduction (not shown) of the voltammetric charge value as the storage time increases. These films are called deactivated.

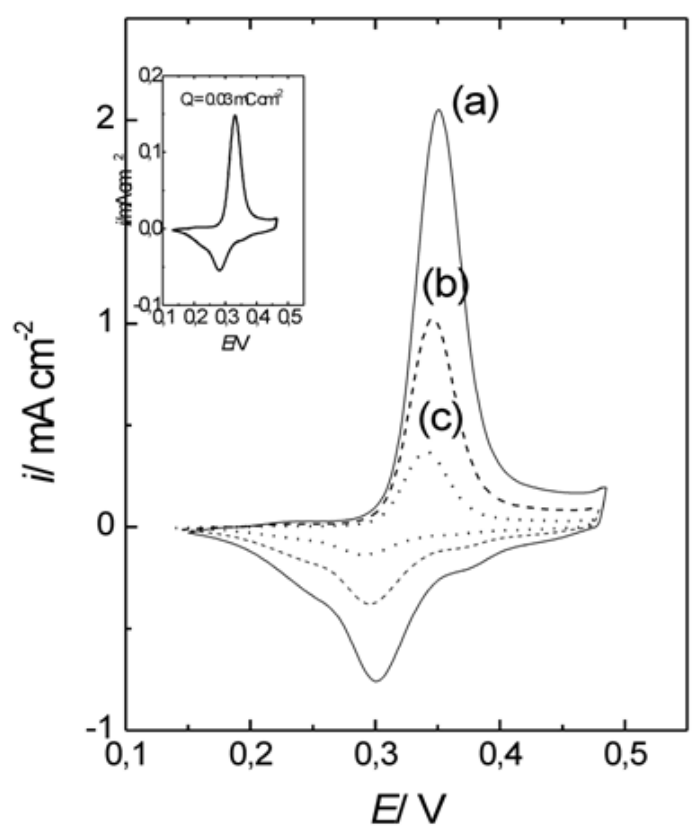

Figure 1. Stable cyclic voltammograms at $0.02 \mathrm{~V} \mathrm{~s}^{-1}$ for nondeactivated $\mathrm{Au} / \mathrm{Ni}$-hydroxide modified electrodes in a $0.1 \mathrm{M} \mathrm{NaOH}$ solution. Voltammetric charge values of the nickel hydroxide films: (a) $4 \mathrm{mC} \mathrm{cm}^{-2}$; (b) $Q=2 \mathrm{mC} \mathrm{cm}^{-2}$; (c)

$Q=0.8 m C \mathrm{~cm}^{-2}$.Inset $: Q=0.03 \mathrm{mC} \mathrm{cm}^{-2}$.

Steady-state experiments were also performed with deactivated and nondeativated nickel hydroxide gold-modified electrodes in contact with a $0.1 \mathrm{M} \mathrm{NaOH}+2 * 10^{-3} \mathrm{M}$ deferasirox solution. Current-potential (I-E) curves were recorded at different electrode rotation rates $(\Omega)$. Steady-state experiments were performed using a measurement system comprising a PAR model 175 universal programmer and a PAR model 173 potentiostat-galvanostat. A Philips model $8134 x-y 1-y 2$ recorded was used to record the stationary current-potential curves. The electrode rotation rate $\Omega$ was controlled with home-made equipment that allowed one to select a constant $\Omega$ value in the range $50 \mathrm{rev} \mathrm{min}^{-1}<\Omega<8000$ rev $\mathrm{min}^{-1}$. In some cases higher electrode rotation speed values (> $10000 \mathrm{rev} \mathrm{min}^{-1}$ ) were employed. This was controlled with a digital phototachometer (Power Instruments model 891).

Impedance spectra were also recorded following a 30-min application of the steady-state potential ranging from $0.35 \mathrm{~V}$ to 0.5 $\mathrm{V}$. Impedance values were determined at seven discrete frequencies per decade with a signal amplitude of $5 \mathrm{mV}$. The validation of the impedance spectra was done by using Kramers-Kronig transformations. Impedance measurements in the frequency range 0.01 $\mathrm{Hz}-10 \mathrm{kHz}$ were performed with a PAR 309 system.

AR grade chemicals were employed throughout. $\mathrm{Ni}\left(\mathrm{NO}_{3}\right)_{2}$ Fluka was employed. $\mathrm{NaOH}$ (Merck) was used without purification. The solution were prepared with water purified using a Millipore Milli-Q system. Deferasirox was synthesized as described in [10].

\section{RESULTS AND DISCUSSION}

\subsection{Cyclic Voltammetry Experiments}

The surface coverage $\left(\Gamma_{A u-N i}\right)$ of the different Au/Ni modified electrodes shown in Fig. 1 can be estimated from the voltammetric oxidation (or reduction) charge $(Q)$ evaluated in the supporting electrolyte solution $(0.1 \mathrm{M} \mathrm{NaOH})$ by using the equation $\Gamma_{A u-N i}=Q / n F A$, where $Q$, is anodic (or cathodic) voltammetric charge corresponding to the oxidation (or reduction) process, assuming that all the nickel redox sites are electroactive on the voltammetric time scale, $F$ is the Faraday's constant, $A$ is the geometric surface area of the gold electrode and $n$, is the number of electrons transferred in $\mathrm{Ni}$ (II) $\longrightarrow \mathrm{Ni}$ (III) oxidation reaction. The redox system corresponding to the peaks shown in Fig. 1 was attributed to the redox process $\mathrm{Ni}(\mathrm{II}) / \mathrm{Ni}(\mathrm{III})$. The process can be represented by the following electrochemical reaction [12]:

$$
\mathrm{Ni}(\mathrm{OH})_{2}+\mathrm{HO}^{-} \longleftrightarrow \mathrm{NiO}(\mathrm{OH})+\mathrm{H}_{2} \mathrm{O}+\mathrm{e}^{-}
$$

or as done in $[13,14]$, by:

$$
\mathrm{Ni}(\mathrm{OH})_{2} \longleftrightarrow \mathrm{NiO}(\mathrm{OH})+\mathrm{H}^{+}+\mathrm{e}^{-}
$$

Although the voltammetric response of an immediately prepared nickel hydroxide film undergoes profound changes during the first cycles, a stable voltammogram is obtained after about 150 cycles. $\mathrm{Ni}(\mathrm{OH})_{2}$ and $\mathrm{NiOOH}$ are considered good electronic conductors with a structure of poor or not barrier character. A schematic reaction scheme was proposed in [11] for the mediated oxidation of deferasirox on the nickel hydroxide surface:

$$
\begin{aligned}
& \mathrm{Ni}(\mathrm{II}) \longrightarrow \mathrm{Ni}(\mathrm{III})+1 \mathrm{e}^{-} \\
& \mathrm{Ni}(\mathrm{III})+\text { drug } \longrightarrow \text { Product }+\mathrm{Ni}(\mathrm{II})
\end{aligned}
$$




\subsection{RDEV Experiments with nondeactivated and deac- tivated nickel hydroxide-gold modified electrodes in the presence of deferasirox}

It is often indicated that nickel hydroxide films retain their electroactivity, after storage without use in an alkaline solution, for several weeks [1-5]. This is very important for electroactive materials employed in analytical applications. Development of analytical sensors with long-term stability will remain a mainstay to meet needs for routine clinical, environmental and industrial applications. However, we find that although nondeactivated films maintain unaltered their electroactivity for more than 200 potential cycles under continuous use, if they are stored in an alkaline solution without use for different time periods, undergo an irreversible deactivation. Although this deactivation process becomes not so evident from the slight distortion of the voltammetric response, it is more noticeable from the steady state current-potential experiments in the presence of an electroactive solute (see below).

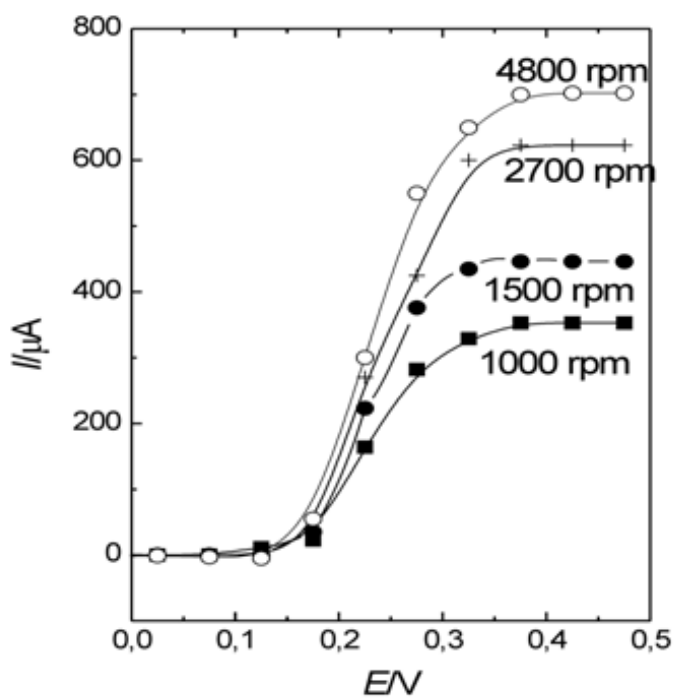

Figure 2. Steady-state current-potential (I-E) curves for a nondeactivated nickel hydroxide gold modified electrode, $Q=0.3 \mathrm{mC} \mathrm{cm}^{-2}\left(\Gamma=4.44 * 10^{-9}\right.$ moles $\left.\mathrm{cm}^{-2}\right)$ in contact with a $0.1 \mathrm{M}$ $\mathrm{Na}(\mathrm{OH})+2 * 10^{-3} \mathrm{M}$ deferasirox solution. Different rotation rates indicated on the figure.

Three series of nickel hydroxide gold-modified electrodes were prepared in this work to quantitatively study their deactivation by employing RDEV. Each series was conformed by 6 hydroxide films. The voltammetric charge of the 6 films of each series was $0.3 ; 2$ and $4 \mathrm{mC} \mathrm{cm} \mathrm{cm}^{-2},\left(\Gamma=0.44 ; 2.96\right.$ and $5.92 * 10^{-8}$ moles $\left./ \mathrm{cm}^{2}\right)$, respectively. That is, each series was constituted by 6 films all of the same voltammetric charge. Then, each one of the 6 nickel hydroxide films corresponding to each series, after being equilibrated within the potential region $0.0 \mathrm{~V}<\mathrm{E}<0.6 \mathrm{~V}$ in the $0.1 \mathrm{M} \mathrm{NaOH}$ solution, was stored (without use) in a deaerated $0.1 \mathrm{M} \mathrm{NaOH}$ solution for different time periods. That is, each one of the 6 films of each series was subjected to the same storage time sequence (first column in Table 1). RDEV experiments were performed with both, nondeactivated and deactivated films, in the presence of the electroactive substrate deferasirox.

Fig. 2 shows steady-state current-potential (I-E) curves, at different electrode rotation rates, $\Omega$, for the nondeactivated nickel hydroxide film of $0.3 \mathrm{mC} \mathrm{cm} \mathrm{cm}^{-2}$. As can be seen from this figure, diffusion-limited currents are observed at $\mathrm{E}>0.45 \mathrm{~V}$ (vs. SCE) for the deferasirox oxidation. The anodic limiting currents, at each electrode rotation rate, are independent on the nickel hydroxide charge value and follow the Levich equation (Fig. 3). The behavior observed in Fig. 3, for nondeactivated films of different voltammtric charges would be related to a rapid electron-transfer mediation at the nickel hydroxide/deferasirox solution interface. Fig. 4 shows steady-state current-potential curves $(I v s . E)$ at different $\Gamma$ values for the nickel hydroxide film $\left(Q=0.3 \mathrm{mC} \mathrm{cm}^{-2}\right)$ after to be stored in the alkaline solution for $10 \mathrm{~h}$ without use. As can be seen by comparing Fig. 2 with Fig. 4, the anodic limiting current for the deactivated film increases with the rotation rate increase until a given value, from which it becomes $\Omega$ independent. Fig. 5 shows the $I_{\text {Lim }, a}$ vs. $\Omega^{1 / 2}$ dependences for the nondeactivated film of $Q=0.3 \mathrm{mC} \mathrm{cm}^{-2}$ and the same film deactivated after storage in an alkaline solution for different time periods.

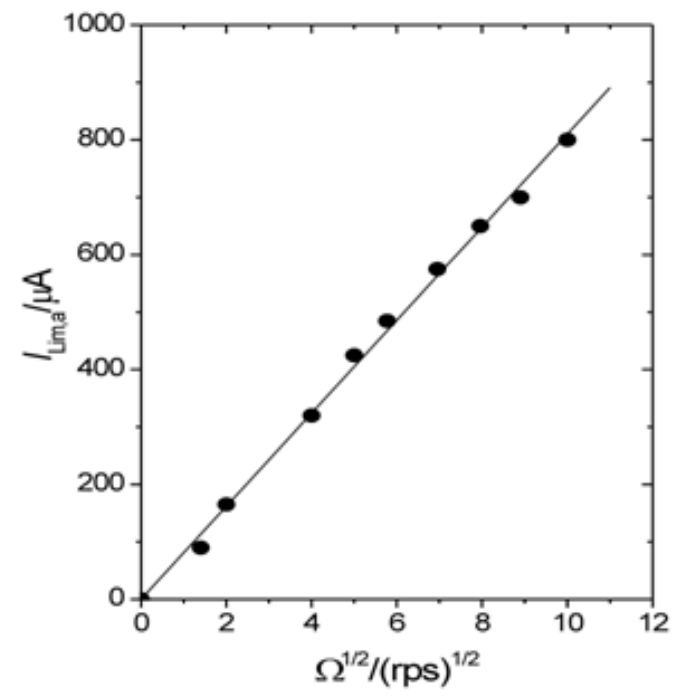

Figure 3. Levich representation $\left(I_{\text {Lim, } a}\right.$ vs. $\left.\Omega^{1 / 2}\right)$ for a nondeactivated nickel hydroxide gold modified electrode in contact with a $0.1 \mathrm{M}$ $\mathrm{Na}(\mathrm{OH})+2 * 10^{-3} \mathrm{M}$ deferasirox solution.

While the nondeactivated film gives a Levich dependence, a constant current value is obtained after a given $\Omega$ value for the deactivated films. This constant current is indicative of a deactivation process. As can be seen from Fig. 5, as the higher is the storage time the lower is the electrode rotation rate at which a constant current value is reached and then, more deactivated is the film. The constant current value achieved for different deactivated nickel hydroxide films by employing a fixed storage time, depends on their voltammetric charge value. Fig. 6 shows the $I_{\text {Lim }, a}$ vs. $\Omega^{1 / 2}$ dependences for a nondeactivated film of $Q=2 \mathrm{mC} \mathrm{cm}^{-2}$ and the same film after to be deactivated by employing the same sequence of storage times as for a film of $Q=0.3 \mathrm{mC} \mathrm{cm}{ }^{-2}$. As 


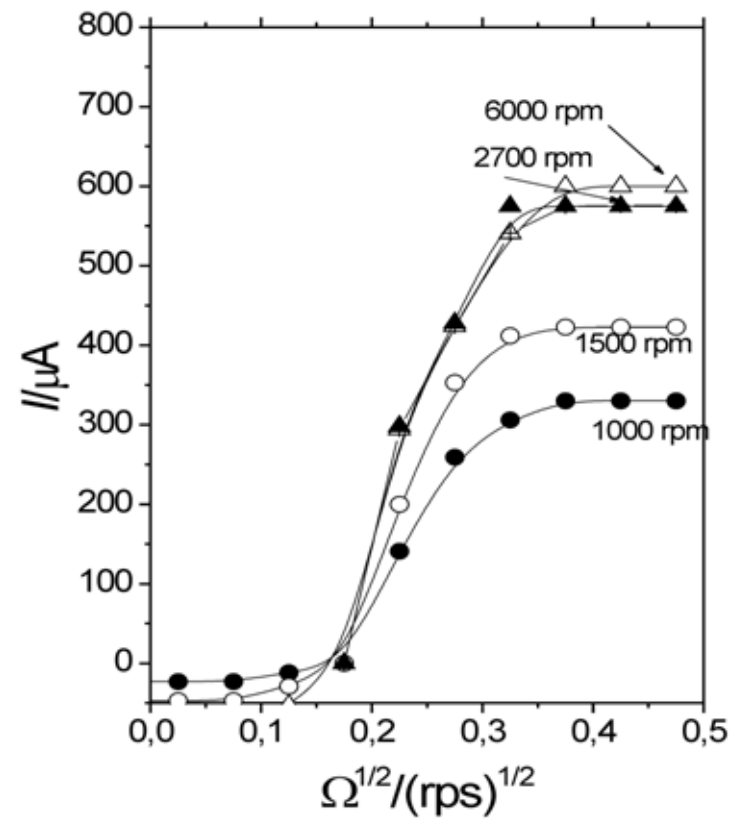

Figure 4. Steady-state current-potential (I-E) curves for a deactivated nickel hydroxide gold-modified electrode

$Q=0.3 \mathrm{mC} \mathrm{cm} \mathrm{cm}^{-2}\left(\Gamma=4.44 * 10^{-9}\right.$ moles $\left.\mathrm{cm}^{-2}\right)$ in contact with a $0.1 \mathrm{M}$ $\mathrm{Na}(\mathrm{OH})+2 * 10^{-3} \mathrm{M}$ deferasirox solution. Different rotation rates indicated on the figure. Storage time: $10 \mathrm{~h}$.

can be seen by comparing Fig. 5 and Fig. 6, the $I_{\text {const }}$ for the same storage time is observed at higher electrode rotation rate as the higher is the voltammetric charge value of the film. In this regard, nickel hydroxide films of high voltammetric charge become less deactivated than thin ones for a fixed storage time. The rows of Table 1 allows one comparing the $I_{\text {const }}$ values for nickel hydroxide films of different $Q$ values, which were deactivated by employing the same storage time in an alkaline solution.

\subsection{Interpretation of the RDEV Experiments}

The steady state experiments above described seem to indicate that deactivation of nickel hydroxide films could be associated to a restriction in the charge transport process across the film. Then, interpretation of nickel hydroxide films deactivation was made in this work on the basis of the Eq. (1) [15]:

$$
I_{\text {const }}=n F A D_{c t}\left(c_{o} / \phi_{f i l m}\right)
$$

Eq. (1) was previously employed to describe the charge transport processes in other materials such as electroactive redox polymers that also contain active redox sites and then, these polymers are able to act as mediators in redox reactions [16-21]. In Eq. (1), $c_{o}$ is the total volumetric concentration of redox sites into the electroactive film and $\phi_{\text {film }}$ the film thickness. The parameter $c_{o}$ is equal to $c_{R e d}+c_{O x}$, where $c_{R e d}$ and $c_{O x}$ are the volumetric concentration of reduced and oxidized redox sites, respectively $\left(\mathrm{Ni}(\mathrm{II}) / \mathrm{Ni}(\mathrm{III})\right.$ redox sites). $D_{c t}$ represents a measure of the charge transport rate within the film. Then, in the case of nickel hydroxide films $D_{c t}$ should represent the rate of electron transport across

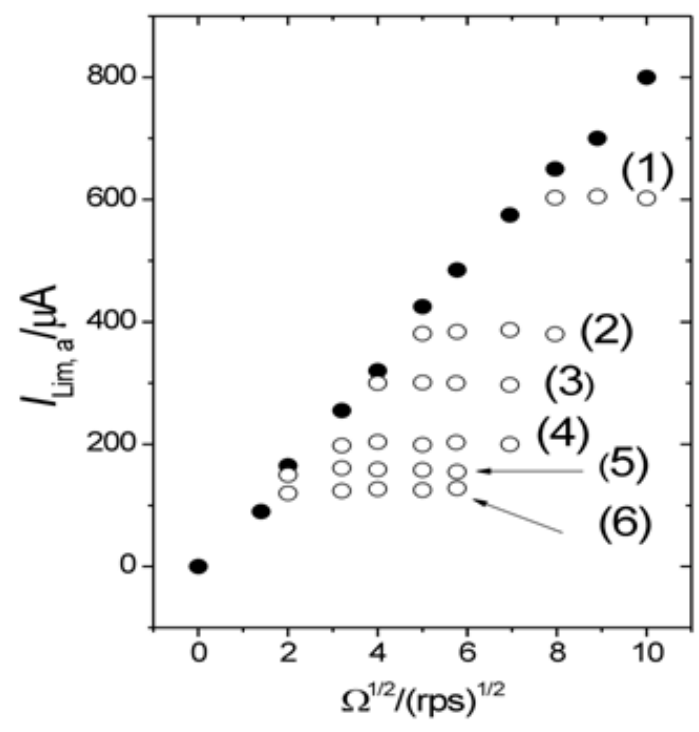

Figure 5. Levich representations ( $I_{\text {Lim }, a}$ vs. $\Omega^{1 / 2}$ ) for a nondeactivated nickel hydroxide film $(\bullet)$ in contact with a $0.1 \mathrm{M} \mathrm{Na}(\mathrm{OH})+2 * 10^{-3} \mathrm{M}$ deferasirox solution and the same film deactivated after storage in an alkaline solution for different time periods (1) $10 \mathrm{~h}$; (2) $20 \mathrm{~h}$; (3) $25 \mathrm{~h}$; (4) $45 \mathrm{~h}$; (5) 65 ; (6) $85 \mathrm{~h}$.

$Q=0.3 \mathrm{mC} \mathrm{cm}^{-2}\left(\Gamma=4.44 * 10^{-9}\right.$ moles $\left.\mathrm{cm}^{-2}\right)$.

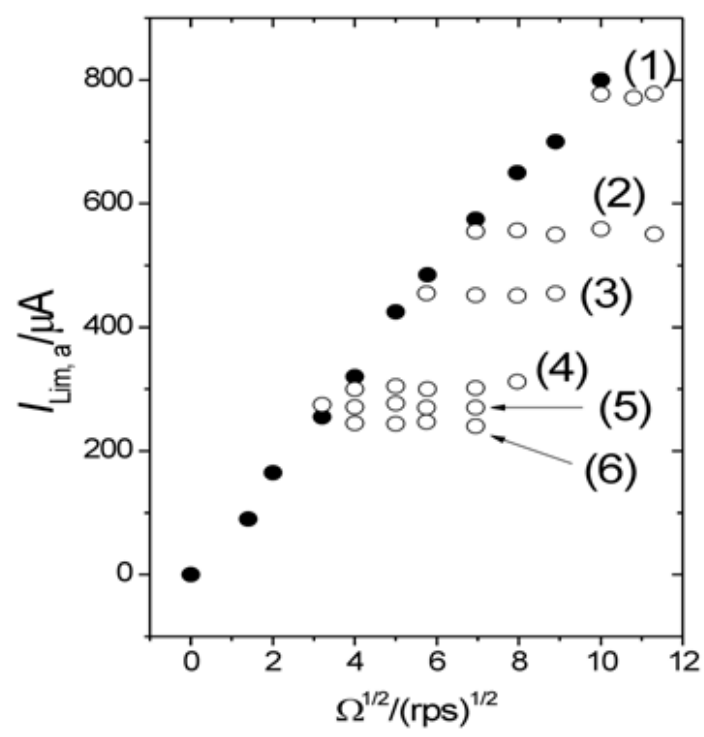

Figure 6. Levich representations $\left(I_{\text {Lim }, a}\right.$ vs. $\left.\Omega^{1 / 2}\right)$ for a nondeactivated nickel hydroxide film $(\bullet)$ in contact with a $0.1 \mathrm{M} \mathrm{Na}(\mathrm{OH})+2 * 10^{-3} \mathrm{M}$ deferasirox solution and the same film deactivated after storage in an alkaline solution for different time periods (1) $10 \mathrm{~h}$; (2) $20 \mathrm{~h}$; (3) $25 \mathrm{~h}$; (4) $45 \mathrm{~h}$; (5) 65 ; (6) $85 \mathrm{~h}$. $Q=2 m C \mathrm{~cm}^{-2}\left(\Gamma=2.96 * 10^{-8}\right.$ moles $\left.\mathrm{cm}^{-2}\right)$.

the $\mathrm{Ni}(\mathrm{II}) / \mathrm{Ni}(\mathrm{III})$ redox sites. The number $n$ expresses the number of transferred electrons in the redox process of the electroactive material, $A$ is the electrode area and $F$ the Faraday's constant. The 
Table 1. $I_{\text {const }}$ VALUES FOR DEACTIVATED NICKEL HYDROXIDE FILMS OF DIFFERENT THICKNESS.

\begin{tabular}{|c|c|c|c|}
\hline${ }^{a} t / h$ & $\begin{array}{c}{ }^{b} 10^{6} I_{\text {const }} / \mu A \\
Q=0.3 \mathrm{mC} \mathrm{cm}^{-2}\end{array}$ & $\begin{array}{l}{ }^{b} 10^{6} I_{\text {const }} / \mu A \\
Q=2 \mathrm{mC} \mathrm{cm}\end{array}$ & $\begin{array}{l}{ }^{b} 10^{6} I_{\text {const }} / \mu A \\
Q=4 m C \mathrm{~cm}^{-2}\end{array}$ \\
\hline 10 & 607 & 775 & 850 \\
\hline 20 & 375 & 550 & 712 \\
\hline 25 & 300 & 455 & 600 \\
\hline 45 & 200 & 320 & 452 \\
\hline 60 & 160 & 290 & 400 \\
\hline 80 & 157 & 270 & 407 \\
\hline
\end{tabular}

Electrode area: $0.7 \mathrm{~cm}^{2}$.

${ }^{a}$ Storage time in a $0.1 \mathrm{M} \mathrm{NaOH}$ solution (a different film was employed for each storage time).

${ }^{b} I_{\text {const }}$ was obtained in a $0.1 \mathrm{M} \mathrm{NaOH}+2 \mathrm{mM}$ Deferasirox solution. $Q$ is the voltammetric charge value for the oxidation process $\mathrm{Ni}(\mathrm{II}) / \mathrm{Ni}(\mathrm{III})$ in the $0.1 \mathrm{M} \mathrm{NaOH}$ solution.

limiting current value at which $I_{\text {Lim, } a}\left(=I_{\text {const }}\right)$ becomes constant (see Fig. 5 and Fig. 6) can be considered as a representation of the maximum flux of charge transported across the electroactive film.

On the assumption that nickel hydroxide films are uniform and homogeneous, the film thickness can be expressed as $\phi_{f i l m}=$ $\Gamma / c_{o}$. Then, Eq. (1) can be written as:

$$
I_{\text {const }}=n F A D c t\left(c_{o}^{2} / \Gamma\right)
$$

While $I_{\text {const }}$ (Fig. 5 and Fig. 6) and $\Gamma$ are experimental parameters, the interpretation of diffusion coefficients $\left(D_{c t}\right)$ in solid materials depends on the model employed to describe the charge propagation and sometimes on the technique used in its measurement. In this regard the rate of charge transport in solid materials can vary over several orders of magnitude $\left(10^{-7}-10^{-14} \mathrm{~cm}^{2} \mathrm{~s}^{-1}\right)$.

On the assumption that co remains constant the deactivation effect could only be attributed to a reduction of the charge propagation rate, $D_{c t}$. The existence of a constant current $I_{\text {const }}$ in a deactivated film can be explained in the following way. As one increases the flux of electroactive species ( $\Omega$ increase) from the bulk solution, then if the flux exceeds the supply of charge from the gold electrode through the nickel hydroxide film to the electrolyte interface, the rate-limiting step will shift from the limiting transport of the electroactive species to the limiting transport of the charge through the nickel hydroxide film. This consideration seems to be verified by the fact that $I_{\text {const }}$ is observed at a lower electrode rotation rate as more deactivated is the nickel hydroxide film for a given voltammetric charge (or film thickness). However, $I_{\text {const }}$ also depends on the nickel hydroxide voltammetric charge for a given storage time. These findings seem to indicate a charge transport process limited by both the degree of deactivation and film thickness. Fig. 7 shows the $I_{\text {const }}$ vs. storage time dependence for each one of the 3 series of nickel hydroxide films employed in this work (each series conformed by 6 films) whose voltammetric charge values are $0.3,2$ and $4 \mathrm{mC} \mathrm{cm}^{-2}$, respectively. This representation shows again that for a constant storage time a thin nickel hydroxide film deactivates more than a thick one.

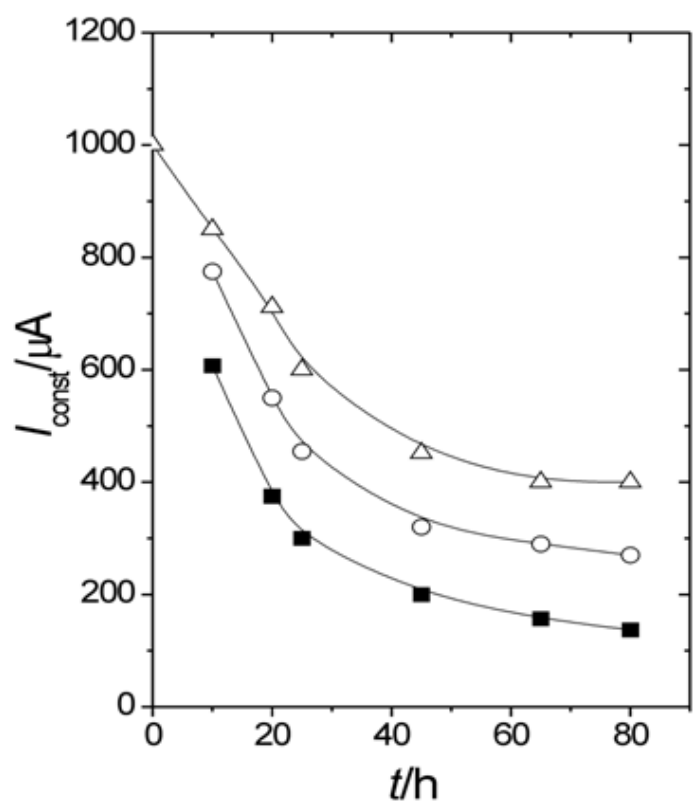

Figure 7. $I_{\text {const }}$ vs. storage time dependence for different voltammetric charge values: $(\square) Q=0.3 \mathrm{mC} \mathrm{cm}^{-2}$; $(\bigcirc) Q=2 \mathrm{mC} \mathrm{cm}^{-2}$; $(\square)$ $Q=4 m \mathrm{C} \mathrm{cm}^{-2}$. Solution: $0.1 \mathrm{M} \mathrm{Na}(\mathrm{OH})+2 * 10^{-3} \mathrm{M}$ deferasirox.

With regard to transport properties, experimental $I_{\text {const }}$ values for different deactivated films were employed in Eq. (2) to extract the transport parameter $D_{c t} c_{o}^{2}$ as a function of the storage time (Table 2). As can be seen from Table 2, $D_{c t} c_{o}^{2}$ decreases as the storage time increases for each film thickness and also, at a constant storage time a thick film exhibits a higher charge transport parameter as compared with a thin one. As was indicated, on the assumption that $c_{o}$ remains nearly constant, the deactivation effect could only be attributed to a reduction of the charge propagation rate, $D_{c t} c_{o}$. One can not obtain absolute values of the diffusion coefficient for the charge transport from experimental $I_{\text {const }}$ values due to the lack of data about $c_{o}$ for electrochemically synthesized nickel hydroxide films. Thus, from experimental $I_{\text {const }}$ values, only the parameter $\left(D_{c t} c_{o}^{2}\right)$ was estimated. $D_{c t} c_{o}^{2}$ values for each $Q$ value and different storage times are also collected in Table 2 .

With regard to $D_{c t}$, as was indicated, it should represent the rate of electron transport across the $\mathrm{Ni}(\mathrm{II}) / \mathrm{Ni}(\mathrm{III})$ redox sites. The conduction mechanism of some materials containing redox sites [22], is considered in terms of the electron hopping model with the participation of the redox sites as acceptor or donor sites. The $D_{c t} c_{o}^{2}$ decrease for a nickel hydroxide film stored in an alkaline solution could be strictly attributed to either a $D_{c t}$ decrease or $c_{o}$ decrease or both of them. On the assumption that $c_{o}$ (total redox sites volumetric concentration) remains constant, the $D_{c t}$ decrease could be explained in terms of the increase of the hopping distance between active redox active sites ( $\mathrm{Ni}(\mathrm{II}) / \mathrm{Ni}$ (III) because after deactivation some redox sites becomes inactive. In this connection, the electron diffusion coefficient, $D_{c t}$, has been expressed in terms of the mean distance between adjacent active redox sites [23], according to $D_{c t}=\left(\alpha^{2} k_{o}\right)$, where $k_{o}$ is the intermolecular electron-transfer rate constant and $\alpha$ is the mean 
Table 2. $D_{C T} c_{o}^{2}$ VALUES FOR DIFFERENT DEACTIVATED NICKEL HYDROXIDE FILMS

\begin{tabular}{|c|c|c|c|}
\hline${ }^{a} t / h$ & $\begin{array}{c}{ }^{b} 10^{1} 6 D_{c t} c_{o}^{2 /} \\
m o l^{2} \mathrm{~cm}^{-4} s^{-1} \\
Q=0.3 m C \mathrm{~cm}^{-2}\end{array}$ & $\begin{array}{c}{ }^{b} 10^{1} 6 D_{c t} c_{o}^{2} / \\
m^{2} l^{2} \mathrm{~cm}^{-4} s^{-1} \\
Q=2 m C \mathrm{~cm}^{-2}\end{array}$ & $\begin{array}{c}{ }^{b} 10^{1} 6 D_{c t} c_{o}^{2} / \\
m o l^{2} c^{-4} s^{-1} \\
Q=4 m C c^{-2}\end{array}$ \\
\hline 10 & 0.39 & 3.39 & 7.45 \\
\hline 20 & 0.24 & 2.41 & 6.24 \\
\hline 25 & 0.19 & 1.99 & 5.26 \\
\hline 45 & 0.17 & 1.40 & 3.96 \\
\hline 60 & 0.10 & 1.27 & 3.50 \\
\hline 80 & 0.09 & 1.18 & 3.52 \\
\hline
\end{tabular}

Electrode area: $0.7 \mathrm{~cm}^{2}$.

${ }^{a}$ Storage time in a $0.1 \mathrm{M} \mathrm{NaOH}$ solution (a different film was employed for each storage time).

${ }^{b} D_{c t} c_{o}^{2}$ was obtained in a $0.1 \mathrm{M} \mathrm{NaOH}+2 \mathrm{mM}$ Deferasirox solution. $Q$ is the voltammetric charge value for the oxidation process $\mathrm{Ni}(\mathrm{II}) / \mathrm{Ni}(\mathrm{III})$ in the $0.1 \mathrm{M} \mathrm{NaOH}$ solution.

distance between two adjacent redox sites. The hopping rate, $k_{o}$, exhibits an exponential dependence on $\alpha$, through the energy $-U(x+\alpha)$ of a state with an electron in the position $x$ along the current direction (see Eq. (23) in Ref. [23]). Thus, the $D_{c t}$ decrease could explain the electron current $I_{\text {const }}$ decrease with the increase of the storage time. As was indicated, the interpretation of diffusion coefficients in solid materials depends on the model employed to describe the charge propagation and sometimes on the technique used in its measurement.

With regard to $c_{o}$, we have attempted to estimate this parameter for our nickel hydroxide films from data reported in other papers. An ellipsometric study of nickel hydroxide electrodes formed by ex situ chemical precipitation is reported in [24]. Different ellipsometric parameters of nickel hydroxide films, including the ellipsometric thickness, as a function of the voltmmetric charge are presented in [24]. These parameters approach to limiting values as electrode charge is increased. The dependency of the nickel hydroxide film thickness on the voltammetric charge extracted from table 1 of Ref. [24], allows one estimating a $c_{o}$ value. Although is likely that the proper characteristics of nickel hydroxide layers obtained by chemical precipitation used in [24] are not exactly the same for layers cathodically produced, a $c_{o}$ value was extracted from data presented in [24]. By employing the ellipsometric thickness value $\left(d_{\text {ellip }}=95 \mathrm{~nm}\right)$ given in [24] for a charge value around $4 m \mathrm{~m} \mathrm{~cm}^{-2}$, and considering $c_{o}=\Gamma / d_{\text {ellip }}=Q / n F A d_{\text {ellip }}$, a $c_{o}$ value around $3.86 * 10^{-3} \mathrm{~mol} \mathrm{~cm}{ }^{-3}$ is obtained.

At this point it is interesting to compare $D_{c t} c_{o}^{2}$ values obtained in this work for nickel hydroxide films with those obtained for other materials such as electroactive redox polymers that also are able to act as mediators in redox reactions [16-21]. In this regard, the electroactive polymer poly $(o$-aminophenol $)$ immediately synthesized, that acts as mediator in the presence of different electroactive solutes $\left(\mathrm{Fe}(\mathrm{CN})_{6}{ }^{4-/ 3-}\right.$ and hydroquinonebenzoquinone) exhibits a $D_{c t} c_{o}^{2}$ value around $7.32 * 10^{-14} \mathrm{~mol}^{2} \mathrm{~s}^{-1} \mathrm{~cm}$ [18]. This $D_{c t} c_{o}^{2}$ value for poly (o-aminophenol) arises from wellknown diffusion coefficient $\left(D_{c t}\right)$ and total redox sites concentration (co) values of $2.93 * 10^{-9} \mathrm{~cm}^{2} \mathrm{~s}^{-1}$ and $5 * 10^{-3} \mathrm{~mol} \mathrm{~cm}^{-3}$, respectively [19]. As can be seen from Table 2, $D_{c t} c_{o}^{2}$ values for deactivated nickel hydroxide films are lower than the value reported for immediately prepared poly(o-aminophenol) film electrodes. However, the deactivation of the electroactive polymer poly $(o$-aminophenol) by ferric cations was also studied by rotating disc electrode voltammetry and impedance spectroscopy in previous works [20,21]. It was found that the diffusion coefficient values of poly (o-aminophenol) decreases about two orders of magnitude, that is, from $2.93 * 10^{-9} \mathrm{~cm}^{2} \mathrm{~s}^{-1}$ to $2.4 * 10^{-11} \mathrm{~cm}^{2} \mathrm{~s}^{-1}$ [20] as the degree of deactivation increases from 0.1 to 0.6. Thus, a $D_{c t} c_{o}^{2}$ value around $6 * 10^{-16} \mathrm{~mol}^{2} \mathrm{~s}^{-1} \mathrm{~cm}^{-4}$ arises for a deactivated poly(o-aminophenol) film, which is comparable to the value corresponding to a deactivated nickel hydroxide film.

\subsection{Impedance measurements}

Impedance measurements were also performed with nondeactivated and deactivated nickel hydroxide gold-modified electrodes contacting a $0.1 \mathrm{M} \mathrm{Na}(\mathrm{OH})+2 * 10^{-3} \mathrm{M}$ deferasirox solution at potential values $\mathrm{E}>0.35 \mathrm{~V}$. However, impedance spectra were only recorded for the nickel hydroxide films of charge value $Q=2 \mathrm{mC} \mathrm{cm}^{-2}$. Nyquist diagrams at different electrode rotation rates for a nondeactivated nickel hydroxide film are shown in Fig. 8 .

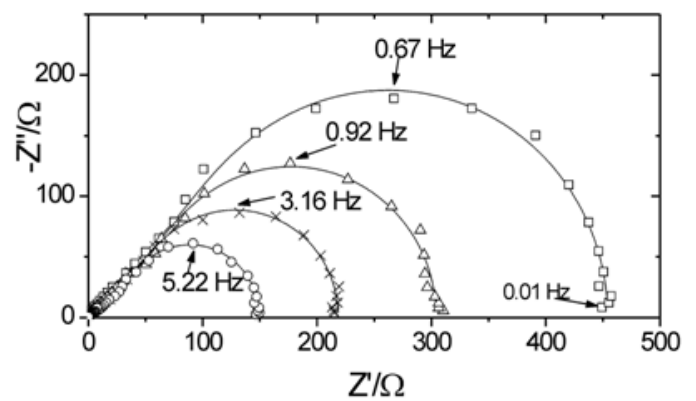

Figure 8. Ac impedance diagrams in the Nyquist coordinates (-Z" versus $\mathrm{Z}$ ) obtained at $\mathrm{E}=0.5 \mathrm{~V}$ for a nondeactivated nickel hydroxide film. The different diagrams correspond to different electrode rotation rates, $\Omega$ : ( $\square) 100 \mathrm{rpm}$; $\triangle$ ) $200 \mathrm{rpm}$; (X) $300 \mathrm{rpm}$; (○) $600 \mathrm{rpm}$. Electrolyte: $0.1 \mathrm{M} \mathrm{Na}(\mathrm{OH})+2 * 10^{-3} \mathrm{M}$ deferasirox solution. $Q=2 \mathrm{mC} \mathrm{cm}^{-2}$. Discrete points are experimental data and continuous lines represent the fitting by using the theory given in [25].

A Warburg region at high frequency, followed by a semicircle, is observed in the impedance diagrams of a nondeactivated film. Impedance diagrams of each one of the six deactivated nickel hydroxide films indicated in Table $1\left(Q=2 \mathrm{mC} \mathrm{cm}^{-2}\right)$ exhibit two loops (Fig. 9). While the loop at low frequency is $\Omega$ dependent, the high-frequency semicircle is independent of this variable. However, the size of the high-frequency semicircle depends on the storage time (Fig. 10). In this regard, at a given $\Omega$ value, the higher the storage time value is, the greater the high-frequency semicircle becomes.

Although several ac impedance diagrams at potential values within the range $0.35 \mathrm{~V}<\mathrm{E}<0.5 \mathrm{~V}$ (versus $\mathrm{SCE}$ ) were recorded for different deactivated nickel hydroxide films, those shown in 


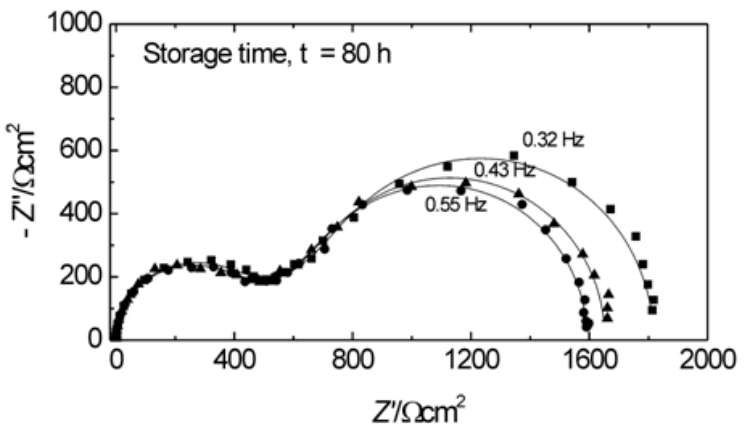

Figure 9. Ac Impedance diagrams in the Nyquist coordinates (-Z" versus $\mathrm{Z}$ ) obtained at $\mathrm{E}=0.5 \mathrm{~V}$ for a deactivated nickel hydroxide film, storage time, $80 \mathrm{~h}$. The different diagrams correspond to different electrode rotation rates, $\Omega:(\boldsymbol{\square}) 1000 \mathrm{rpm} ;(\boldsymbol{\Delta}) 1500 \mathrm{rpm}$; (•) $3000 \mathrm{rpm}$. Electrolyte: $0.1 \mathrm{M} \mathrm{Na}(\mathrm{OH})+2 * 10^{-3} \mathrm{M}$ deferasirox solution. $Q=2 m \mathrm{C} \mathrm{cm}^{-2}$. Discrete points are experimental data and continuous lines represent the fitting by using the theory given in [25].

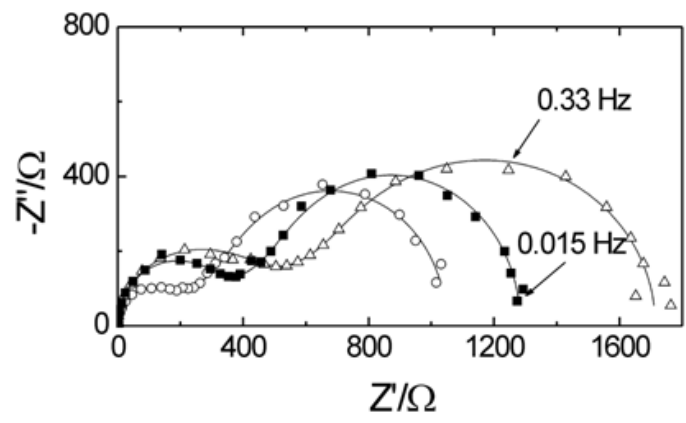

Figure 10. Ac Impedance diagrams in the Nyquist coordinates (-Z" versus $\mathrm{Z}$ ) obtained at $\mathrm{E}=-0.2 \mathrm{~V}$ and a constant electrode rotation rate, $\Omega$ $=3000 \mathrm{rpm}$, for three deactivated nickel hydroxide films: $(\bigcirc) \mathrm{t}=25 \mathrm{~h}$; $(\boldsymbol{\square}) \mathrm{t}=45 \mathrm{~h} ;(\triangle) \mathrm{t}=80 \mathrm{~h}$. Electrolyte: $0.1 \mathrm{M} \mathrm{Na}(\mathrm{OH})+2 * 10^{-3} \mathrm{M}$ deferasirox solution. $Q=2 m \mathrm{C} \mathrm{cm}^{-2}$. Discrete points are experimental data and continuous lines represent the fitting by using the theory given in [25].

Figs. 8 to 10 were considered as representative of the potential region where the redox reaction at the nickel hydroxide/deferasirox solution occurs.

\subsection{Interpretation of ac Impedance diagrams}

The general theory of $a c$ impedance described by Vorotyntsev et al. in [25] was employed to interpret experimental impedance data of the gold-nickel hydroxide film/electrolyte system. It should be indicated that the theory developed in [25] is strictly valid when the charging of interfacial double layers is negligible, i.e., it does not account for the charging of the film | substrate and film | solution layers in parallel with the processes of injection of charge carriers. If this is not the case, a more complete model, such as the one developed by Vorotyntsev in [26], should have to be used. In this model [26], besides the traditional "double-layer" capacitance and interfacial charge-transfer resistances, two additional parameters for each boundary, "interfacial numbers" for each species and "asymmetry factors," are introduced. Although we also fitted our experimental impedance diagrams with the model reported in [26], the fitting did not result much more precise than that using the model given in [25], and furthermore, the increasing mathematical difficulty of determining the numerous parameters of the model given in [26] from experimental data was a major drawback. Then, despite this last theoretical limitation, the model described in [25] concerning a uniform and nonporous film and no penetration of redox species from the solution was employed to interpret our experimental impedance diagrams.

As in the present case one has the modified electrode geometry with a redox active electrolyte solution (m|film|es), Eq. (41) of Ref. [25] (Eq. (3) in this work) must be applied

$$
\begin{array}{r}
Z_{m \mid \text { film } \mid e s}=R_{m \mid f}+R_{f}+R_{s}+\left[Z_{e}^{f \mid s} R_{i}^{f \mid s}+W_{f} Z_{12}^{m}\right]\left(Z_{e}^{f \mid s}+\right. \\
\left.R_{i}^{f \mid s}+2 W_{f} \operatorname{coth} 2 v\right)^{-1}
\end{array}
$$

where

$$
Z_{12}^{m}=Z_{e}^{f \mid s}\left[\operatorname{coth} v+\left(t_{e}-t_{i}^{2}\right) \tanh v\right]+R_{i}^{f \mid s} 4 t_{i}^{2} \tanh v+W_{f} 4 t_{i}^{2}
$$

In Eqs. (3) and (4):

$v=\left[\left(j w \phi_{p}^{2}\right) / 4 D\right]^{1 / 2}$ is a dimensionless function of the frequency $\omega, \phi_{p}$ is the film thickness, $D$ is the binary electronion diffusion coefficient, and $t_{i}$ and $t_{e}$ are the migration (high frequency) bulk-film transference numbers for anions and electrons, respectively. $D$ is defined as $D=2 D_{i} D_{e}\left(D_{e}+D_{i}\right)^{-1}$ and $t_{i, e}=D_{i, e}\left(D_{e}+D_{i}\right)^{-1}$, where De and Di are the diffusion coefficients for the electrons and ion species, respectively.

$W_{f}=\left[v / j \omega \phi_{p} C_{p}\right]=\Delta R_{f} / v$ is a Warburg impedance for the electron-ion transport inside the electroactive film. $\Delta R_{f}\left(=\phi_{p} / 4 D C_{p}\right)$ is the amplitude of the Warburg impedance inside the film, and $C_{p}$ is the redox capacitance per unit volume.

$R_{f}\left(=\phi_{p} / \kappa\right)$ is the high-frequency bulk-film resistance, $R_{s}$ the ohmic resistance of the bulk solution ( $\kappa$ is the high-frequency bulk conductivity of the film), $R_{m \mid f}$ is the metal|film interfacial electron-transfer resistance, and $R_{i}^{f \mid s}$ is the film|solution interfacial ion-transfer resistance.

$Z_{e}^{f \mid s}=\left(R_{e}^{f \mid s}+W_{s}\right)$ is the electronic impedance, where $R_{e}^{f \mid s}$ is the interfacial electron-transfer resistance at the film|solution interface, and $W_{s}$ is the convective diffusion impedance of redox species in solution, which contains the bulk concentrations of ox(red) forms, $c_{o x}\left(c_{r e d}\right)$, and their diffusion coefficients inside the solution, $D_{o x}\left(D_{\text {red }}\right)$. Also, it contains the Nernst layer thickness, $\delta$.

$$
\begin{aligned}
& R_{e}^{f \mid s} \text { is defined as } \\
& \quad R_{e}^{f \mid s}=R T\left(n F^{2} k_{o} c_{r e d}\right)^{-1}
\end{aligned}
$$

where $k_{o}$ is the rate constant of the reaction between the film and the redox active forms in solution. Diffusion of the redox forms from the bulk solution to the film|solution interface can be regarded as stationary through the diffusion layer thickness, expressed in $\mathrm{cm}$ by

$$
\delta=4.98 D_{o x, r e d}^{1 / 3} \eta^{1 / 6} \Omega^{-1 / 2}
$$


where $\eta$ is the kinematic viscosity of the solution in the same units as $D_{\text {ox,red }}$, and $\Omega$ the rotation rate of the disk electrode in rpm. The rest of the constants have their usual meaning. This model also includes the impedance behavior of the electoactive material contacting the inactive electrolyte (absence of the redox couple in solution) by considering $Z_{e}^{f \mid s} \longrightarrow \infty$ in Eq. (3).

\subsection{Dependence of the different charge-transport pa- rameters of nickel hydroxide films on the storage time}

Continuous lines on the impedance diagrams shown from Figs. 8 to 10 are simulated curves calculated by using Eq. (3).

A good fitting was observed for the different impedance diagrams. The fitting procedure by using Eq. (3) was based on the CNLS (Complex Nonlinear Squares) method. A rigorous fitting procedure was performed. Six replicate measurements for each storage time were carried out, and the error structure was assessed following the method recommended by Agarwal et al. [27-29] and Orazem [30]. The standard deviation for the real $\left(\sigma_{Z r}\right)$ and imaginary $\left(\sigma_{Z j}\right)$ parts of the impedance followed the form proposed by Orazem (see eq. (8) of Ref. [30])

$$
\sigma_{Z r}=\sigma_{Z j}=\alpha|Z j|+\beta|Z r|+\gamma|Z|^{2} R m^{-1}+\delta
$$

where $R m$ is the current measuring resistor used for the experiment, $Z r$ is the real part of the impedance, and $Z j$ is the imaginary part of the impedance. $\alpha, \beta, \gamma$ and $\delta$ are constants that have to be determined. The values of these scaling factors were $\alpha=0$, $\beta=9.17 * 10^{-3} \pm 0.009 * 10^{-3}, \gamma=5.4 * 10^{-5} \pm 0.31 * 10^{-5}$ and $\delta=7.9 * 10^{-3} \pm 0.2 * 10^{-3}$. Then, continuous lines in Figs. 8 to 10 represent the weighted complex nonlinear least-squares fit to the data. The regression was weighted by the inverse of the variance of the stochastic part of the measurement. In all conditions the weighted sum of the square of the residuals was below one [30].

In the simulations the number of transferred electrons, $n$, was assumed to be 1 , and a typical diffusion coefficient value of $D_{\text {ox } \text {,red }}=1.0 * 10^{-5} \mathrm{~cm}^{2} \mathrm{~s}^{-1}$ was considered for the deferasirox species in solution. Also, the bulk concentrations of the redox substrate species were considered equal $\left(c_{o x}=c_{\text {red }}=2 *\right.$

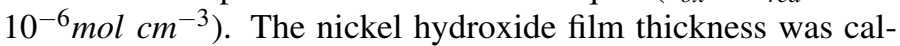
culated on the basis of the expression $\phi_{f i l m}=\Gamma / c_{o}$. By considering a charge value of $Q=2 \mathrm{mC} \mathrm{cm}^{-2}$, a nickel hydroxide film thickness about $27 \mathrm{~nm}$ results. The value of the total redox site concentration obtained from RDEV measurements (3.86*

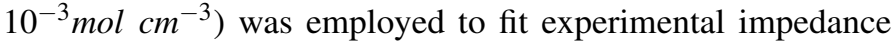
plots. The ohmic resistance of the solution in contact with the nickel hydroxide films, $R_{S}$, was measured. A value $R_{S} \sim 2.19$ $\mathrm{ohm} \mathrm{cm} 2$ was obtained. Then, by considering the high-frequency intercept of impedance diagrams of nickel hydroxide films in the presence and in the absence of deferasirox as Ro, the highfrequency bulk nickel hydroxide film resistance, $R_{f}$, was calculated as $R_{f}=R_{o}-R_{S}$ [31]. The latter value varied within the range $3.09<R_{f}<5.34 \mathrm{ohm} \mathrm{cm}^{2}$ and it seems not to be strongly dependent on the storage time. Then, $R_{f}$ and $R_{S}$ values were imposed in the fitting. The remnant parameters contained in
Eq. (3) $\left(R_{m \mid f}, R_{i}^{f \mid s}, R_{e}^{f \mid s}, C_{p}, D_{e}\right.$ and $\left.D_{i}\right)$ were calculated from the experimental impedance data by the fitting procedure described above. The first four parameters $\left(C_{p}, R_{m \mid f}, R_{i}^{f \mid s}\right.$ and $\left.R_{e}^{f \mid s}\right)$ were varied without restraints during the fitting. However, some reference values were considered for $D_{e}$ and $D_{i}$. For the nondeactivated nickel hydroxide film thickness used in this work $\left(\phi_{p}=\right.$ $27 \mathrm{~nm}), D_{e}$ and $D_{i}$ values were allowed to vary within the range $10^{-7} 10^{-11} \mathrm{~cm}^{2} \mathrm{~s}^{-1}$, in such a way that diffusion coefficient values lower than $10^{-11}$ were considered unrealistic for these thick films. That is, $D_{e}$ and $D_{i}$ values lower than $10^{-11}$ were only obtained from impedance diagrams (not shown) of very thin nickel hydroxide films $\left(Q_{T, \text { Red }}=0.04 \mathrm{mC} \mathrm{cm}^{-2}, \phi_{p}=3 \mathrm{~nm}\right)$, where incomplete coating of the metal area by the thin nickel hydroxide film is possible. A contribution of the interfacial capacitance, $C_{H}$, also considered as a fitting parameter, was included in order to represent the actual impedance diagrams from the calculated ones.

Different charge-transport and charge-transfer parameters versus the storage time dependences, extracted from the fitting procedure described above, are shown from Figs. 11 to 16.

The $C_{p}$ versus storage time dependence is shown in Fig. 11. Starting from a $C_{p}$ value of about $87 \mathrm{~F} \mathrm{~cm}^{-3}$, for a nondeactivated film, a decrease of $C_{p}$ with increasing the storage time is observed. It should be kept in mind that these $C_{p}$ values correspond to the oxidized state of the nickel hydroxide film.

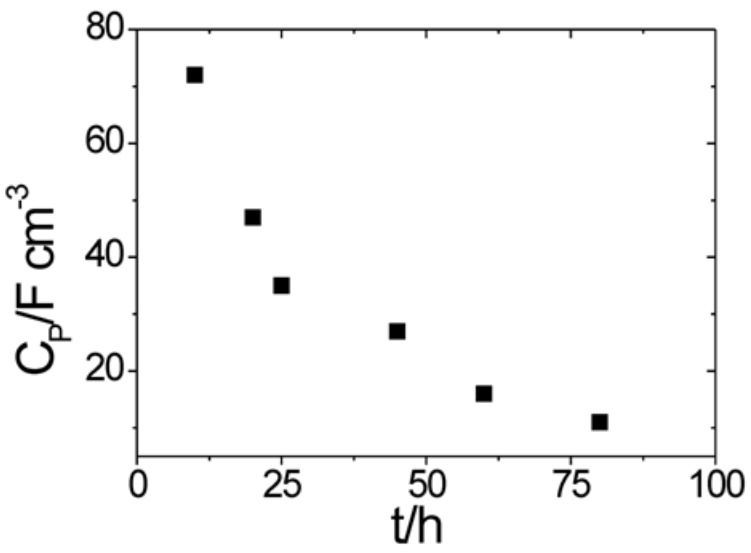

Figure 11. Redox capacitance $\left(C_{p}\right)$ as a function of the storage time, $t$. The value $87 \mathrm{~F} \mathrm{~cm}^{-3}$ for $t=0$ corresponds to a nondeactivated nicel hydroxide film. Electrolyte: $0.1 \mathrm{M} \mathrm{Na}(\mathrm{OH})+2 * 10^{-3} \mathrm{M}$ deferasirox solution. $Q=2 m \mathrm{C} \mathrm{cm}^{-2}$.

Nickel hydroxide film-solution interfacial ion-transfer resistance $\left(R_{\text {ion }}^{\mathrm{Ni}(\mathrm{OH})_{2} \text { elect }}\right)$ and Gold/Ni $(\mathrm{OH})_{2}$ interfacial electron-transfer resistance $\left(R^{\text {gold }} / \mathrm{Ni}(\mathrm{OH})_{2}\right)$ on storage time dependences are shown in Figs. 12 and 13, respectively. $R_{\text {ion }}^{\mathrm{Ni}(\mathrm{OH})_{2} / \text { elect }}$ as a function of the storage time exhibits a different feature as compared with $R^{\text {gold }} / \mathrm{Ni}(\mathrm{OH})_{2}$. That is, while $R^{\text {gold }} / \mathrm{Ni}(\mathrm{OH})_{2}$ seems to Increase continuously within the whole storage time range, $R_{\text {ion }}^{\mathrm{Ni}(\mathrm{OH})_{2} / \text { elect }}$ firstly exhibits a slight increase within the range $0<t<25 h$ and then, a strong increase is observed within the range $25 h<t<80 h$. Also, the magnitude of $R_{\text {ion }}^{\mathrm{Ni}(\mathrm{OH})_{2} / \text { elect }}$ and $R^{\text {gold } / \mathrm{Ni}(\mathrm{OH})_{2}}$ change within 
the whole storage time range is different. $R_{\text {ion }}^{\mathrm{Ni}(\mathrm{OH})_{2} \text { elect }}$ change is around one order of magnitude lower than $R^{\text {gold }} / \mathrm{Ni}(\mathrm{OH})_{2}$ change. This difference could indicate that the high-frequency semicircle on impedance diagrams (Figs. 8 to 10) is mainly determined by $R^{\text {gold } / \mathrm{Ni}(\mathrm{OH})_{2}}$. The increase of interfacial $R^{\text {gold } / \mathrm{Ni}(\mathrm{OH})_{2}}$ resistance could be due to an increasing number of inactive sites at the Gold $\mid \mathrm{Ni}(\mathrm{OH})_{2}$ interface with the increase of deactivation.

Nickel hydroxide/electrolyte interfacial electron-transfer resistance $\left(R_{\text {electron }}^{\mathrm{Ni}(\mathrm{OH})_{2} \text { elect }}\right)$ values were extracted from Eq. (5) using $k_{o}$ as fitting parameter $\left(0.001<k_{o}<1000 \mathrm{~cm} \mathrm{~s}^{-1}\right)$. The feature of $R_{\text {electron }}^{\mathrm{Ni}(\mathrm{OH})_{2} \text { elect }}$ versus storage time dependence (Fig. 14) is similar to $R^{\text {gold }} / \mathrm{Ni}(\mathrm{OH})_{2}$ versus storage time dependence (Fig. 13). However, the $R_{\text {electron }}^{\mathrm{Ni}(\mathrm{OH})_{2} \text { elect }}$ values are around 20 times lower than $R^{\text {gold }} / \mathrm{Ni}(\mathrm{OH})_{2}$ values. Also, it is interesting to note that the $R_{\text {electron }}^{\mathrm{Ni}(\mathrm{OH})_{2} \mid \text { elect }}$ change is lower than the $R_{\text {ion }}^{\mathrm{Ni}(\mathrm{OH})_{2} / \text { elect }}$ change, particularly at high storage times. The increase of interfacial $R_{\text {electron }}^{\mathrm{Ni}(\mathrm{OH})_{2} \mid \text { elect }}$ resistance could be due to an increasing number of inactive sites at the $\mathrm{Ni}(\mathrm{OH})_{2} \mid$ solution interface with the increase of deactivation.

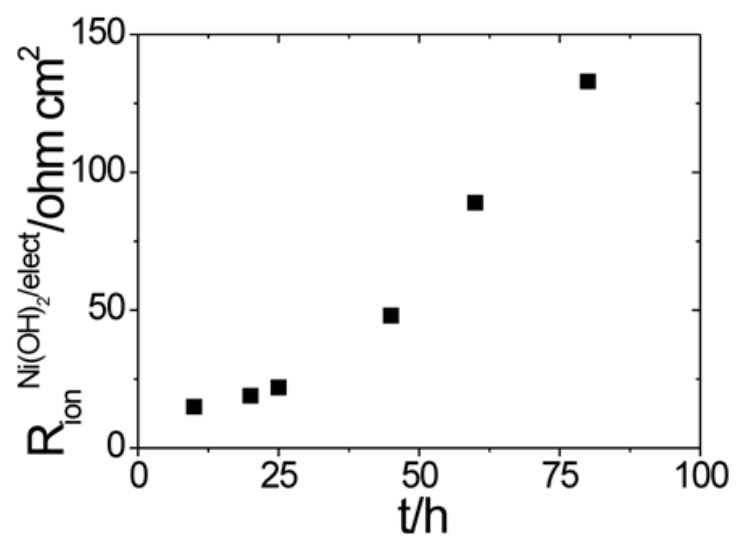

Figure 12. Nickel hydroxide film-solution interfacial ion-transfer resistance as a function of the storage time. Electrolyte: $0.1 \mathrm{M} \mathrm{Na}(\mathrm{OH})$ $+2 * 10^{-3} \mathrm{M}$ deferasirox solution. $Q=2 \mathrm{mC}^{-2}$.

Ion and electron diffusion coefficients versus storage time dependences are shown in Figs. 15 and 16, respectively. Both diffusion coefficients decrease with the storage time increase. As was proposed from RDEV data, the decrease of $D_{\text {electron }}$ with the increase of the storage time could be attributed to an increase of the hopping distance between remnant redox active sites after nickel hydroxide deactivation. $D_{\text {electron }}$ values are nearly one order of magnitude higher than $D_{\text {ion }}$ values. In the present work, relative diffusion coefficient values $\left(D_{\text {electron }}>D_{\text {ion }}\right)$ refer to the oxidized state of nickel hydroxide films. Another interesting difference between $D_{\text {electron }}$ and $D_{\text {ion }}$ versus the storage time dependences can be observed by comparing Fig. 15 with Fig. 16 . While $D_{\text {ion }}$ remains nearly constant for low storage times $(0<$ $\mathrm{t}<25 \mathrm{~h}$ ), $D_{\text {electron }}$ decreases continuous and rapidly within this storage time range. This finding seems to indicate that although ion motion always controls the charge-transport process at nickel hydroxide films, the influence of the electron motion on the whole

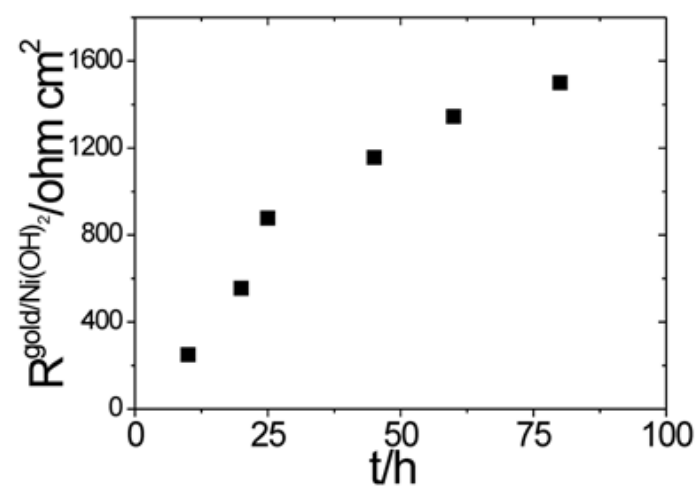

Figure 13. Gold/Ni(OH) $)_{2}$ interfacial electron-transfer resistance $\left(R^{\text {gold }} / \mathrm{Ni}(\mathrm{OH})_{2}\right)$ as a function of the storage time. Electrolyte: $0.1 \mathrm{M}$ $\mathrm{Na}(\mathrm{OH})+2 * 10^{-3} \mathrm{M}$ deferasirox solution. $Q=2 \mathrm{mC} \mathrm{cm}^{-2}$.

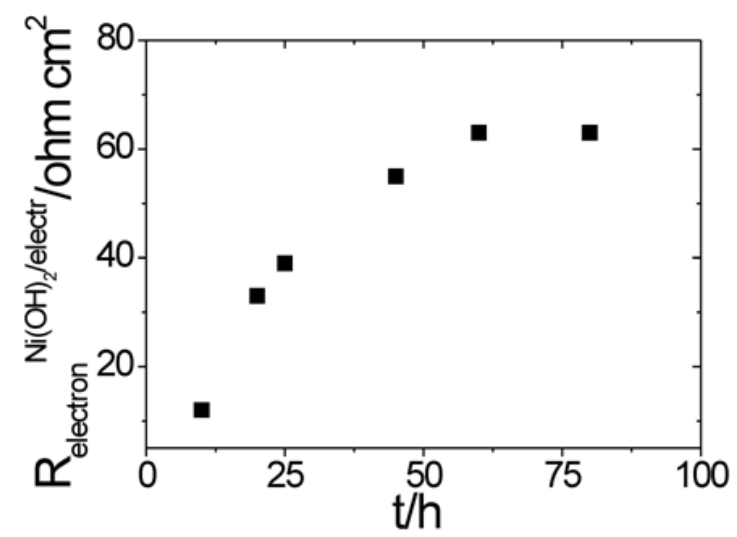

Figure 14. Interfacial electron-transfer resistance $\left(R_{\text {electron }}^{\mathrm{Ni}(\mathrm{OH})_{2} \mid \text { elect }}\right.$ as a function of the storage time. Electrolyte: $0.1 \mathrm{M} \mathrm{Na}(\mathrm{OH})+2 * 10^{-3} \mathrm{M}$ deferasirox solution. $Q=2 m C \mathrm{~cm}^{-2}$.

charge-transport process becomes more pronounced at a high storage times. Then, a break seems to be observed at around $25 \mathrm{~h}$, in the $D_{\text {ion }}$ versus the storage time dependence. The break also becomes evident in nickel hydroxide film-solution interfacial iontransfer resistance as a function of the storage time. (Fig. 12). It is possible that both parameters $R_{i o n}^{\mathrm{Ni}(\mathrm{OH})_{2} /{ }^{\text {elect }}}$ and $D_{i o n}$ are related to proton movements across the nickel hydroxide film|solution interface and inside the nickel hydroxide film, respectively. In this regard, the nickel hydroxide electrode is the positive plate of many rechargeable battery systems such as the nickel/cadmium, nickel/hydrogen and nickel/metal hydrides. It has been proposed that both charge and discharge in these systems are controlled by the solid-state diffusion of protons [32]. Thus, during the discharge (reduction) a proton diffuses from the nickel hydroxide film/electrolyte interface into the active material and an electron enters across the conductive substrate/nickel hydroxide interface. During the charge (oxidation) the proton diffuses to the nickel hydroxide film/electrolyte interface to react with an hydroxyl ion to form water. 


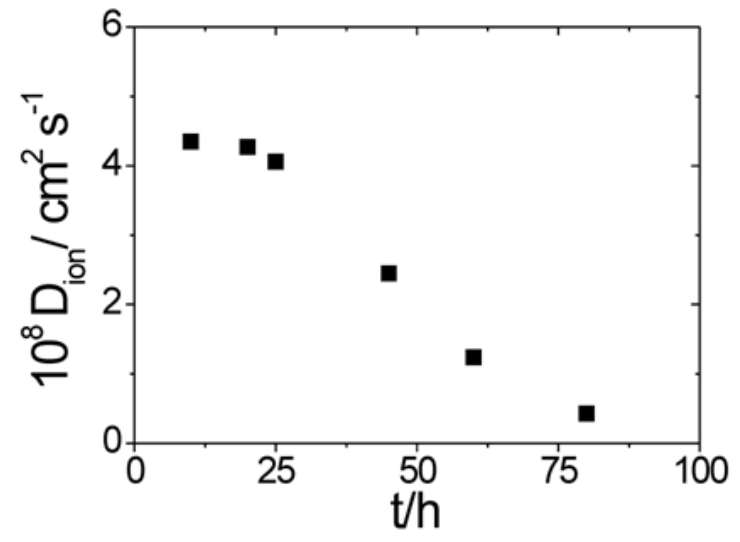

Figure 15. Ion diffusion coefficient $\left(D_{\text {ion }}\right)$ as a function of the storage time. Electrolyte: $0.1 \mathrm{M} \mathrm{Na}(\mathrm{OH})+2 * 10^{-3} \mathrm{M}$ deferasirox solution. $Q=2 m C \mathrm{~cm}^{-2}$.

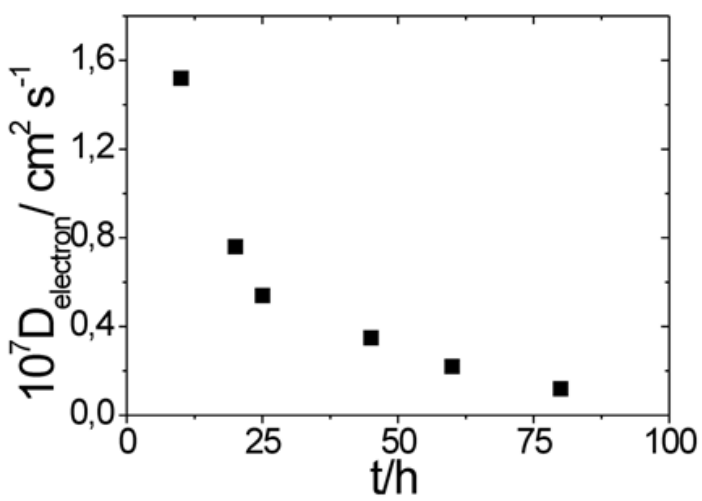

Figure 16. Electron diffusion coefficient $\left(D_{\text {election }}\right)$ as a function of the storage time. Electrolyte: $0.1 \mathrm{M} \mathrm{Na}(\mathrm{OH})+2 * 10^{-3} \mathrm{M}$ deferasirox solution. $Q=2 m C \mathrm{~cm}^{-2}$.

Several researchers have reported data on the solid-state diffusion coefficient of protons in the nickel hydroxide material using different electrochemical techniques (see [31] and references cited therein). A great discrepancyis observed between the proton diffusion coefficient values reported by the different researchers.It is found that diffusion coefficient of protons decreases from $3.4^{*} 10^{-8} \mathrm{~cm}^{2} \mathrm{~s}^{-1}$ to $3.7 * 10^{-9} \mathrm{~cm}^{2} \mathrm{~s}^{-1}$ as the electrode changes from fully charged to $30 \%$ state of charge. The value of the diffusion coefficient further decreases by another one and a half order of magnitude to $6.4 * 10^{-11} \mathrm{~cm}^{2} \mathrm{~s}^{-1}$ at the completely discharged state.Then, our values of $D_{\text {ion }}$ around $10^{-8} \mathrm{~cm}^{2} \mathrm{~s}^{-1}$ (Fig. 15) for the oxidized state of the nickel hydroxide film seems to be in coincidence with proton diffusion coefficient values reported for other researchers [31].

With regard to $C_{H}$ values, starting from a value of around $25 \mu \mathrm{F}$ $\mathrm{cm}^{2}$ for a nondeactivated nickel hydroxide film, $C_{H}$ decreases in a nearly continuous way as the storage time increases, reaching a value of about $10.4 \mu \mathrm{F} \mathrm{cm}$ for $\mathrm{t}=80 \mathrm{~h}$ (not shown). The $C_{H}$ decrease is similar to the $R^{g o l d} / \mathrm{Ni}(\mathrm{OH})_{2}$ increase (Fig. 13). Again, this effect could be assigned to the creation of inactive gaps in the redox site configuration at the nickel hydroxide film $\mid$ gold interface with deactivation.

\section{CONCLUSIONS}

Nickel hydroxide films electrochemically synthesized on a gold base electrode undergo an irreversible deactivation under storage in an alkaline solution. Although the phenomenon is visible on the voltammetric response in the sole presence of the supporting electrolyte solution $(0.1 \mathrm{M} \mathrm{NaOH})$, it is more clearly detected by employing Rotating Disc Electrode Voltammetry when a redox reaction occurs at the $\mathrm{Au}-\mathrm{Ni}(\mathrm{OH})_{2}$ electrolyte interface. The comparison of steady state current-potential curves at different electrode rotation rates for both nondeactivated and deactivated films in the presence of the electroactive solute deferasirox, allowed one obtaining a charge propagation rate which decrease with the increase of the storage time. The degree of deactivation seems to depend on the nickel hydroxide film voltammetric charge. Thick films $\left(Q>4 m C \mathrm{~cm}^{2}\right)$ are less deactivated (remain more conductive) than thin ones for a fixed storage time.The application of an impedance model, which assumes the existence of an homogenous and continuous nickel hydroxide film in contact with an electroactive redox solution, allows one obtaining electron and ion diffusion coefficient values and different interfacial chargetransfer resistances. Ion diffusion coefficient values seem to be in agreement with proton diffusion coefficient values reported for nickel hydroxide in the field of rechargeable batteries. While both ion and electron diffusion coefficient values decrease with the deactivation of nickel hydroxide films, the different interfacial resistances increase as the storage time of the nickel hydroxide film increases.

From the practical viewpoint, as nickel hydroxide is often employed as electroactive material in the determination of different organic and biologically important products, an immediately synthesized film should be used in each analysis. The results of this work allowed us not only to obtain some information about the durability and long-term stability with potential cycling and storage of a nickel hydroxide-modified electrode but also to gain further insights into the charge-propagation process at this modified electrode.

\section{Acknowledgments}

The author gratefully acknowledges the Consejo Nacional de Investigaciones Científicas y Técnicas (CONICET) and also the Facultad de Ciencias Exactas, National University of La Plata (UNLP).

\section{References}

[1] S. Berchmans, H. Gomathi, and G. P. Rao, "Electrooxidation of alcohols and sugars catalysed on a nickel oxide modified glassy carbon electrode," Journal of Electroanalytical Chemistry, vol. 394, no. 1, pp. 267-270, 1995.

[2] Y. L. Lo and B. J. Hwang, "Kinetics of ethanol oxidation on electroless ni-p/sno2/ti electrodes in koh solutions," Journal of The Electrochemical Society, vol. 142, no. 2, pp. 445-450, 1995. 
[3] S. Majdi, A. Jabbari, and H. Heli, "A study of the electrocatalytic oxidation of aspirin on a nickel hydroxide-modified nickel electrode," Journal of Solid State Electrochemistry, vol. 11, no. 5, pp. 601-607, 2007.

[4] K. V. Gobi, K. Tokuda, and T. Ohsaka, "Monomolecular films of a nickel (ii) pentaazamacrocyclic complex for the electrocatalytic oxidation of hydrogen peroxide at gold electrodes," Journal of Electroanalytical Chemistry, vol. 444, no. 2, pp. 145-150, 1998.

[5] M. Jafarian, M. Mahjani, H. Heli, F. Gobal, and M. Heydarpoor, "Electrocatalytic oxidation of methane at nickel hydroxide modified nickel electrode in alkaline solution," Electrochemistry communications, vol. 5, no. 2, pp. 184188, 2003.

[6] S. Majdi, A. Jabbari, H. Heli, and A. Moosavi-Movahedi, "Electrocatalytic oxidation of some amino acids on a nickelcurcumin complex modified glassy carbon electrode," Electrochimica acta, vol. 52, no. 14, pp. 4622-4629, 2007.

[7] S. Shibli, K. Beenakumari, and N. Suma, "Nano nickel oxide/nickel incorporated nickel composite coating for sensing and estimation of acetylcholine," Biosensors and Bioelectronics, vol. 22, no. 5, pp. 633-638, 2006.

[8] S.-Y. Yi, H.-Y. Chang, H.-h. Cho, Y. C. Park, S. H. Lee, and Z.-U. Bae, "Resolution of dopamine and ascorbic acid using nickel (ii) complex polymer-modified electrodes," Journal of Electroanalytical Chemistry, vol. 602, no. 2, pp. 217-225, 2007.

[9] G. Kontoghiorghes, K. Pattichis, K. Neocleous, and A. Kolnagou, "The design and development of deferiprone (11) and other iron chelators for clinical use: targeting methods and application prospects," Current medicinal chemistry, vol. 11, no. 16, pp. 2161-2183, 2004.

[10] G. J. Kontoghiorghes, "Clinical use, therapeutic aspects and future potential of deferiprone in thalassemia and other conditions of iron and other metal toxicity," Drugs Today (Barc), vol. 37, pp. 23-35, 2001.

[11] M. Hajjizadeh, A. Jabbari, H. Heli, A. Moosavi-Movahedi, A. Shafiee, and K. Karimian, "Electrocatalytic oxidation and determination of deferasirox and deferiprone on a nickel oxyhydroxide-modified electrode," Analytical biochemistry, vol. 373, no. 2, pp. 337-348, 2008.

[12] J. Vilche and A. Arvia, "Kinetics and mechanism of the nickel electrode-ii. acid solutions containing a high concentration of sulphate and nickel ions," Corrosion Science, vol. 18, no. 5, pp. 441-463, 1978.

[13] A. Seghiouer, J. Chevalet, A. Barhoun, and F. Lantelme, "Electrochemical oxidation of nickel in alkaline solutions: a voltammetric study and modelling," Journal of Electroanalytical Chemistry, vol. 442, no. 1, pp. 113-123, 1998.

[14] P. Häring and R. Kötz, "Nanoscale thickness changes of nickel hydroxide films during electrochemical oxidation/reduction monitored by in situ atomic force microscopy," Journal of Electroanalytical Chemistry, vol. 385, no. 2, pp. 273-277, 1995.
[15] S. Trasatti, H. Gerischer, and C. Tobias, "Advances in electrochemical science and engineering, 2vch," 1992.

[16] G. O. Ybarra, C. A. Moina, M. Inés Florit, and D. Posadas, "Redox mediation at electroactive polymer coated electrodes: Mechanistic diagnosis criteria from steady state polarization curves," Journal of Electroanalytical Chemistry, vol. 609, no. 2, pp. 129-139, 2007.

[17] G. Ybarra, C. Moina, M. I. Florit, and D. Posadas, "Current rectification by mediating electroactive polymers," Electrochimica Acta, vol. 53, no. 11, pp. 3955-3959, 2008.

[18] A. Bonfranceschi, A. Pérez Córdoba, S. Keunchkarian, S. Zapata, and R. Tucceri, "Transport across poly ( ${ }_{i} i_{i} o_{i} / i_{i}$ aminophenol) modified electrodes in contact with media containing redox active couples. a study using rotating disc electrode voltammetry," Journal of Electroanalytical Chemistry, vol. 477, no. 1, pp. 1-13, 1999.

[19] F. Rodríguez Nieto, D. Posadas, and R. Tucceri, "Effect of the bathing electrolyte concentration on the charge transport process at poly (o-aminophenol) modified electrodes. an ac impedance study," Journal of Electroanalytical Chemistry, vol. 434, no. 1, pp. 83-91, 1997.

[20] R. Tucceri, "Redox mediation and permeation processes at deactivated poly ( o-aminophenol) films. a study applying rotating disc electrode voltammetry and electrochemical impedance spectroscopy," Journal of Electroanalytical Chemistry, vol. 633, no. 1, pp. 198-206, 2009.

[21] R. Tucceri, "Charge-transfer and charge-transport parameters of deactivated poly (o-aminophenol) film electrodes. a study employing electrochemical impedance spectroscopy," Journal of Electroanalytical Chemistry, vol. 659, no. 1, pp. 83-91, 2011.

[22] J. Bisquert, "Analysis of the kinetics of ion intercalation: ion trapping approach to solid-state relaxation processes," Electrochimica Acta, vol. 47, no. 15, pp. 2435-2449, 2002.

[23] C. E. Chidsey and R. W. Murray, "Redox capacity and direct current electron conductivity in electroactive materials," The Journal of Physical Chemistry, vol. 90, no. 7, pp. 14791484, 1986.

[24] J. Zerbino, C. De Pauli, D. Posadas, and A. Arvia, "Ellipsometry of nickel hydroxide electrodes formed by ex situ chemical precipitation. potential routine and time effects," Journal of Electroanalytical Chemistry, vol. 330, no. 1, pp. 675-691, 1992.

[25] M. Vorotyntsev, C. Deslouis, M. Musiani, B. Tribollet, and K. Aoki, "Transport across an electroactive polymer film in contact with media allowing both ionic and electronic interfacial exchange," Electrochimica acta, vol. 44, no. 12, pp. 2105-2115, 1999.

[26] M. Vorotyntsev, "Impedance of thin films with two mobile charge carriers. interfacial exchange of both species with adjacent media. effect of the double layer charges," Electrochimica acta, vol. 47, no. 13, pp. 2071-2079, 2002. 
[27] P. Agarwal, M. E. Orazem, and L. H. Garcia-Rubio, "Measurement models for electrochemical impedance spectroscopy i. demonstration of applicability," Journal of the Electrochemical Society, vol. 139, no. 7, pp. 1917-1927, 1992.

[28] P. Agarwal, O. D. Crisalle, M. E. Orazem, and L. H. GarciaRubio, "Application of measurement models to impedance spectroscopy ii. determination of the stochastic contribution to the error structure," Journal of the Electrochemical Society, vol. 142, no. 12, pp. 4149-4158, 1995.

[29] P. Agarwal, M. E. Orazem, and L. H. Garcia-Rubio, “Application of measurement models to impedance spectroscopy iii. evaluation of consistency with the kramers-kronig re- lations," Journal of the Electrochemical Society, vol. 142, no. 12, pp. 4159-4168, 1995.

[30] M. E. Orazem, "A systematic approach toward error structure identification for impedance spectroscopy," Journal of Electroanalytical Chemistry, vol. 572, no. 2, pp. 317-327, 2004.

[31] S. Motupally, C. C. Streinz, and J. W. Weidner, "Proton diffusion in nickel hydroxide films measurement of the diffusion coefficient as a function of state of charge," Journal of The Electrochemical Society, vol. 142, no. 5, pp. 1401-1408, 1995. 